\title{
La cuarta revolución industrial
}

\section{The fourth industrial revolution}

Juan Guillermo Patiño Vengoechea ${ }^{1, \star}$
${ }^{1}$ Ingeniera Electrónica, Facultad de Ingenierías, Universidad de San Buenaventura,
Medellín, Colombia.
^electronica@usbmed.edu.co

\section{OPEN ACCESS}

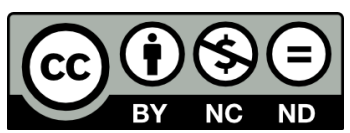

Copyright:(C) 2019 Ingenierías USBmed. La revista Ingenierías USBmed proporciona acceso abierto a todos sus contenidos bajo los términos de la licencia creative commons Atribución- no comercial- SinDerivar 4.0 Internacional (CC BY-NC-ND 4.0)

Editor: Yohana López Rivera, Universidad de San Buenaventura, Medellín, Colombia
Las tres primeras revoluciones industriales, fueron el resultado de la necesidad de la mecanización (Primer telar mecánico 1784, finales del siglo XVIII), la introducción de la producción en masa de energía eléctrica basada en la división del trabajo (Primera línea de producción, mataderos de Cincinnati 1870, principios del siglo $X X$ ) y la utilización de la electrónica y la tecnología de la información para lograr una mayor automatización de fabricación (Primer controlador lógico programable (PLC), Modicon 084 1969, comienzo de la década de 1970). En la actualidad la cuarta revolución industrial ${ }^{a}$ o industria 4.0, difiere a sus antecesoras, ya que se creó a partir de la fusión de tecnologías y de una creciente armonización e integración entre las disciplinas de investigación de las ciencias.

La Industria 4.0, se basa en sistemas robóticos inteligentes, vinculados a la Internet de las cosas, o sistemas de ordenadores en red, robots e inteligencia artificial interactuando con el mundo físico, digital y biológico, a esta fusión se le denomina Sistemas Ciber-físicos.

En esencia, la Industrie 4.0 implicará la integración técnica de Sistemas Ciber-físicos y el uso de Internet de Las cosas y servicio, que traerá consigo cambios fundamentales en la forma en que vivimos, trabajamos y nos relacionamos con los demás e incluso lo que significa ser un humano.

\footnotetext{
${ }^{a}$ Concepto creado por Wolfgang Wahlster, director y CEO del German Research Center for Artificial Intelligence. 2010.
} 